Takeuchi, Y. (2005). What is modernity? Writings of Takeuchi Yoshimi. Ed. by R. Calichman. N. Y: Columbia University Press. 224 p.

The Clash of Ideas: The Ideological Battles that Made the Modern World and Will Shape the Future (2012) Ed. by G. Rose, J. Tepperman. Foreign Affairs [online] Available at: http://files.foreignaffairs.com/legacy/attachments/Clash\%20of\%20Ideas_FB\%20Excerpt_0.pdf (access date: 12.02.2018).

Submission date: 13.02 .2018 .

Федотова Валентина Гавриловна - доктор философских наук, профессор, главный научный сотрудник сектора социальной философии, руководитель научного семинара «Социальная философия и развитие гражданского общества в России» Института философии Российской академии наук. Адрес: 109240, Россия, г. Москва, ул. Гончарная, 12, стр. 1. Тел.: +7 (495)697-98-93. Эл. адреc: val_fedotova@mail.ru

Fedotova Valentina Gavrilovna, Doctor of Philosophy, Professor, Chief Research Fellow, Sector of Social Philosophy; Head, Research Seminar "Social Philosophy and Development of Civil Society in Russia", Institute of Philosophy, Russian Academy of Sciences. Postal address: 12, Bldg. 1, Goncharnaya St., Moscow, Russian Federation, 109240. Tel.: +7 (495) 697-98-93. E-mail: val_fedotova@mail.ru

DOI: $10.17805 /$ zpu.2018.2.7

\title{
Социальное государство в России: история и современность
}

\author{
Г. Ю. КАНАРШ \\ ИНСТИТУТ ФИЛОСОФИИ РАН
}

Настоящая статья посвящена проблеме формирования социального государства в современной России. Несмотря на фиксируемый многими исследователями кризис государства благосостояния на Западе (в связи с глобализацией), социальное государство в нашей стране необходимо создавать. Наличие огромного социального неравенства показывает его отсутствие, невыстроенность.

Автор обращается к генезису построения социального государства в России. Приводятся мнения разных исследователей о том, было ли советское социалистическое государство социальным. Автор присоединяется к той точке зрения, что советское государство не было социальным в подлинном смысле этого слова, поскольку классическое социальное государство включает институт буржуазного общества, посредством которого достигается классовый компромисс. В то же время несомненно, что социалистическое государство, несмотря на свою изначально классовую природу, выполняло важнейшие социальные функции.

В статье описаны основные этапы формирования социального государства в постсоветской России. Автор соглашается с мнением тех исследователей, которые считают, что данное государство в России по-прежнему не сформировано. Главная причина этого существующая в стране политико-экономическая система. Опираясь на ряд исследований экономистов, политологов, автор показывает, что нынешнее «социальное государство» в России выстроено таким образом, что выражает прежде всего интересы господствующего класса - правящей бюрократии. И единственным выходом из этого положения 
является усиление контроля за властью со стороны общества и конкурентных политических институтов.

При существующей системе отношений власти и общества перспективы социального государства в России выглядят достаточно туманными, пока не изменится сама политикоэкономическая структура российского общества.

Ключевые слова: социальное государство; социальная политика; советское государство; социальные классы; классовый компромисс; социальное страхование; бюрократия; демократия; Россия

\section{BВЕАЕНИЕ}

оциальное государство - ключевая проблема современного российского общества. Огромное социальное расслоение, существующее в нынешней России, говорит о невыстроенности социального государства и ставит задачу полноценного развития этого важнейшего общественного института (см.: Канарш, 2018). Несмотря на отмечаемый целым рядом исследователей кризис государства благосостояния в развитых странах (см., например: Аюблинский, 2017; Сидорина, 2013; Федотова, 2005), мы считаем, что социальное государство в России необходимо создавать. Однако при этом возникает вопрос о том, какие причины тормозят процесс создания нормального социального государства в России.

В настоящей статье будут рассмотрены взаимосвязанные вопросы о природе советского социального государства, генезисе социального государства в постсоветской России, а также о тех о трудностях и противоречиях, которые стоят на пути формирования полноценного социального государства в нашей стране.

\section{ГЕНЕЗИС СОЦИААЬНОГО ГОСУААРСТВА \\ В ПОСТСОВЕТСКОЙ РОССИИ}

Прежде чем говорить о сегодняшних реалиях, нельзя обойти вниманием вопрос о том, было ли построено социальное государство в ХХ в. в нашей стране. Как считает, например, социальный философ В. Г. Федотова, в СССР также было создано социальное государство, в основе которого лежали принципы солидарности и заботы о собственных гражданах, однако в отличие от западного государства благосостояния оно не было демократическим (Федотова, 2005: 427). Чем, какими чертами характеризовалось это государство?

Во-первых, әто справедливое (уравнительное) перераспределение, сходные для всех условия жизни и стремление к их улучшению. Во-вторых, социальные услуги государства и его значимость в поддержании таких общественных секторов, как образование, здравоохранение, жилищное строительство, развитие средств коммуникации и связи. В-третьих, забота государства о нравственном и культурном развитии граждан. В-четвертых, это государство было не только солидарным, но и субсидиарным - т. е. предполагало систему социальной защиты (в форме непосредственного финансового участия государства в несении финансового бремени) наиболее уязвимых слоев населения. В целом, как пишет В. Г. Федотова, «советское социалистическое государство изобрело систему справедливости, которая не во всем отвечала своей сущности, но была одним из способов решения этого вопроса» (там же: 429).

В то же время в литературе, посвященной проблеме социального государства, есть точка зрения, что социальное и социалистическое государства - это два принципиально различных типа государства, и за их внешним сходством (солидарность, социальная забота о своих гражданах) скрывается более глубокое различие в самой при- 
роде, в самом типе социальности. Как указывает, например, исследователь этой проблемы философ $\Lambda$. Н. Кочеткова (Кочеткова, 2012), особенность социального государства Запада состоит прежде всего в том, что оно возникает в условиях господства частной собственности и рыночной экономики, а также в обществе, имеющем классовую структуру. А главной задачей социального государства является не изменение природы общественных отношений (как в социалистическом государстве), а достижение социальной стабильности и классового мира. Напротив, природа социалистического государства характеризуется стремлением к кардинальному изменению самого общественно-экономического уклада (переходу от капитализма к социализму), а сам период этого перехода от одной общественно-экономической формации к другой характеризуется открытой диктатурой одних классов (прежде эксплуатируемых) в отношении других (бывших эксплуататоров). Таким образом, вместо сохранения социальной стабильности и классового мира, а также конвергентной социальной основы (сочетания элементов капитализма и социализма) мы видим здесь принципиально иные цели (построение бесклассового общества), как и принципиально иную социально-экономическую основу - в виде полной ликвидации частной собственности и рынка.

Таким образом, признавая в целом, что советское социалистическое государство действительно (а не декларативно) заботилось о своих гражданах, тратило на это колоссальные средства, $\Lambda$. Н. Кочеткова обоснованно пишет следующее: «...приходится сделать вывод о том, что социальное и социалистическое государство - это два разных концептуальных “проекта”, отличающихся между собой по своей сути, целям, задачам и способам решения социальных проблем. Это, по существу, два разных ответа на исторические вызовы эпохи индустриального капитализма, в условиях которого резко обострились классовые противоречия и, как результат, активизировалось гражданское общество. Аругими словами, это два разных решения социального вопроса, возникшего на рубеже XIX-XX вв. во многих странах. <...> Важно отметить, что оба эти проекта практически одновременно возникли в общественном сознании, а затем независимо друг от друга были реализованы в политике XX в.» (там же: 131; курсив источника. $-\Gamma$. К.).

При этом сущностным противоречием советского социалистического государства исследователь считает противоречие между подлинным стремлением государства к увеличению благосостояния населения (и подлинно универсалистской политикой благосостояния, сближающей социальную политику в СССР с социальной политикой, например, скандинавских стран) и одновременно - доминирующим классовым подходом, который в определенные периоды советской истории приводил к открытой дискриминации и даже репрессиям в отношении целых больших слоев населения (например, бывших «эксплуататорских классов», позже - «кулаков»и т. А.). В то же время отказ от классовой политики и переход к построению бесклассового общества в позднесоветский период означал, по мнению Кочетковой, начало падения советского государства, поскольку в этом случае оно утрачивало собственную сущность и, таким образом, больше не соответствовало провозглашенным в рамках марксизма-ленинизма задачам перехода от капитализма к соииализму (там же: 130).

Эти выводы, повторим, представляются безусловно интересными (и эвристически ценными), однако важно подчеркнуть следующее: и в буржуазном социальном государстве, и в советском социалистическом государстве власть осуществляла сильную социальную политику, заботясь о своих гражданах - их материальном положении, 
состоянии здоровья, культурном уровне. И в этом отношении социалистическое государство, при всех важных сущностных отличиях от классического социального государства Запада, до определенных пор мало в чем ему уступало.

Если следовать данной логике, то представляется совершенно справедливым вывод о том, что именно падение коммунистической системы и возвращение страны в русло капиталистического развития на рубеже 1980-1990-х годов открывало путь для создания в России буржуазного социального государства. Во всяком случае, именно в этот период (начало 1990-х годов) начинают складываться все основные предпосылки социального государства: институт частной собственности, рыночная экономика, классовая структура общества (класс предпринимателей и класс наемных работников). В этих условиях чрезвычайно важным оказывается и правовое (конституционное) закрепление самого принципа социального государства (в Конституции 1993 г.), в соответствии с которым Россия провозглашалась таковым.

В то же время возникновение социально-экономических предпосылок, а также законодательное закрепление принципа социального государства в Конституции РФ еще отнюдь не означало действительного воплощения идеи социального государства на практике. Напротив, хорошо известно, что период первой половины и середины 1990-х годов - это чрезвычайно драматичное для российского общества время и в политическом (противостояние ветвей власти, дошедшее до вооруженного столкновения), и в социально-экономическом отношении. Если иметь в виду экономику и социальную сферу, то это - время беспрецедентного падения промышленного производства, резкого сокращения количества рабочих мест, падение престижа рабочих и инженерных профессий, оттока квалифицированных кадров из производства и связанной с ним научной сферы в сферу коммерческую, а также появление новых социально уязвимых слоев населения, которые в условиях крайней финансовой недостаточности фактически остались без материальной поддержки со стороны государства. Поэтому $\Lambda$. Н. Кочеткова делает совершенно справедливый вывод о ситуации в 1990-х годах: «...реальное обеспечение социальных гарантий, предоставляемых государством в форме законодательных установлений, находилось на чрезвычайно низком уровне: реальная ситуация в сфере реализации социальных прав шла прямо вразрез с закрепленными в Конституции и законах правовыми гарантиями. Население России оказалось в радикально новой ситуации, характеризующейся беспрецедентно высоким уровнем всех видов сочиальных рисков» (там же: 136; курсив источника. - Г. К.). При этом здесь же в работе Кочетковой верно отмечается, что социальная инфраструктура, оставшаяся еще со времен СССР (системы образования, здравоохранения, социального обеспечения), в условиях отсутствия попыток ее реформирования фактически функционировала инерционным образом, а личные материальные запасы граждан были к тому времени практически истощены (в условиях либерализации цен и связанной с ней начавшейся гиперинфляции). Поэтому не случайно социально-экономическое положение основной части населения России в тот период характеризуется многими исследователями как адаптачия, или попросту выживание.

В то же время именно в этот период, как мы уже отметили выше, в России начинают закладываться основы социального государства - прежде всего в форме соответствующих правовых установлений, но не только: в начале 1990-х годов в стране в соответствии с новыми социально-экономическими условиями начинает развиваться система сочиального страхования, возникают ключевые для этой системы государст- 
венные учреждения: Пенсионный фонд, Фонд социального страхования, Фонд обязательного медицинского страхования (его федеральное управление и региональные отделения), а также просуществовавший до 2001 г. Государственный фонд занятости населения. Именно эти учреждения должны были играть в условиях новой общественно-экономической формации роль аккумулятора денежных средств для страхования основных социальных рисков и осуществления полноценной социальной политики. «Именно эти фонды, - подчеркивает $\Lambda$. Н. Кочеткова, - существенно облегчили адаптацию населения к рынку, обеспечили социальную стабильность, несмотря на грандиозные потрясения, и заложили основы построения социального государства» (там же: 137).

Если говорить про 2000-е годы, то они известны как период относительной стабилизации и политической, и социально-экономической ситуации в стране, связанный, с одной стороны, с политикой Президента России В. В. Путина, а с другой - с высокими ценами на энергоносители и получением в связи с этим государством огромных доходов от продажи нефти и газа. Эти доходы, как известно, позволили расплатиться по внешним долгам, сформировать бездефицитный бюджет и значительно поднять материальный уровень жизни населения (прежде всего за счет увеличения зарплаты, а также определенных социальных программ). В то же время период президентства Путина - это и время значительно увеличившегося социального расслоения (основы которого были заложены еще в 1990-е годы, прежде всего в связи с массовой приватизацией). Кроме того, внутренние противоречия этого периода (2000-х годов) связаны также с непоследовательностью социальной политики (в частности, с отменой в начале 2000-х годов страховых отчислений работодателей и введением единого социального налога), а также с фактически предпринимавшимися попытками части политической и экономической элиты страны осуществить демонтаж социального государства под видом замены его субсидиарным государством. Последнее представляло собой попытку заменить ключевой для социального государства принцип коллективной ответственности (посредством систем социального страхования, а также налогового перераспределения) принципом самоответственности граждан, лишь в вынужденных случаях дополняемым принципом общественной солидарности (там же: $137-138)$.

В результате в настоящий момент можно говорить лишь о наличии в России необходимых предпосылок для создания социального государства (социально-экономических, правовых, институциональных, ценностных), но как таковое социальное государство в России все еще не сформировано. «Сегодняшний этап развития нашего государства в целом нельзя охарактеризовать как социальное государство», - считает $\Lambda$. Н. Кочеткова (там же: 143). Исследователь предлагает говорить о процессе формирования и становления социального государства в России на основе конституционного императива. В настоящее время стратегической задачей она называет переход от провозглашения принципов социального государства к выработке и внедрению механизмов их реализации (там же: 143).

\section{СОЦИААЬНОЕ ГОСУААРСТВО И ОСОБЕННОСТИ РОССИЙСКОЙ ПОАИТИКО-ЭКОНОМИЧЕСКОЙ СИСТЕМЫ}

Перейдем к тем фундаментальным политико-экономическим обстоятельствам, которые препятствуют формированию социального государства в России. И важнейшее из этих обстоятельств, как считают исследователи, это «рыхлость» государства в Рос- 
сии, т. е. его чрезмерная забюрократизированность вместе с отсутствием подлинного общенационального консенсуса в отношении целей развития страны и фактически сохраняющаяся ситуация приватизированности государства.

Как показал в своей работе о проблеме пауперизма в Англии и Франции русский экономист В. А. Милютин (Милютин, 1946), главная проблема, которая препятствовала становлению цивилизованного капитализма в первой половине XIX в. в Европе и способствовала сохранению бедственного положения рабочего класса, - это проблема фундаментального несовпадения, разнонаправленности интересов трудяшихся масс и буржуазии. Ао тех пор, пока эта проблема не будет решена, писал он, и пока интересы рабочего класса и предпринимателей не станут пересекаться, бедственное положение рабочих будет невозможно прекратить (там же: 171). Понятно, полагаем мы вслед за Милютиным, что естественным образом достигнуть такого пересечения интересов антагонистических классов практически невозможно, однако оно возможно тогда, когда политическая и связанная с ней финансово-экономическая элита начинает осознавать угрозу своему положению, исходящую от формирующегося рабочего движения. Именно благодаря данному обстоятельству и сформировалось первое социальное государство в Европе (германское), которое, исходя из трезвой оценки политической и социально-экономической ситуации, заставило работодателей действовать в «едином поле» с трудящимися массами, вводя определенные законом условия для детского и женского труда, а также формируя соответствующие фонды социального страхования. Точно так же при наличии фундаментального консенсуса между политико-экономическими элитами и основным населением формировались и более поздние государства благосостояния в Европе.

Какова же ситуация в этом плане в России? Как показывает, например, экономист О. А. Александрова (Александрова, 2013), для современной России характерно как раз отсутствие такого фундаментального консенсуса между элитами и массами, и это становится главной причиной того, что социальное государство в нашей стране не развивается (а точнее, следовало бы говорить о его фактическом демонтаже). Как показывает Александрова, для всех моделей социального государства, известных в настоящее время, характерен примерно один и тот же механизм связи между экономикой и социальной сферой, который успешно "работает» одновременно на развитие и той и другой. Этот механизм заключается в наличии, с одной стороны, развитой системы социальных трансфертов, что обеспечивает массовый платежеспособный спрос, а с другой стороны - прогрессивной шкалы налогообложения, благодаря которой удается аккумулировать финансовые ресурсы для а) их последующего частичного перераспределения и б) необходимых вложений в развитие промышленности (инвестиций). Эти элементы дополняются также системой льготного налогообложения для тех или иных групп отечественных производителей, что также стимулирует производство. Таким образом, что характерно именно для социального государства, не экономика и не социальная сфера оказываются однозначно доминирующими, но возникает их плодотворное взаимодействие, взаимообусловленность (там же: $56-57)$.

Что же отличает в этом плане Россию? Как аргументированно показывает исследователь, в нашей стране ситуация прямо противоположна вышеописанной модели, и она принципиально не изменилась по сравнению с концом 2000-х годов. Мы попрежнему имеем плоскую (а не прогрессивную) шкалу налогообложения, регрессивную шкалу отчислений в социальные фонды, отсутствие специальных налогов на на- 
следство и предметы роскоши, крайне низкие ассигнования на социальную сферу и науку, сохраняющуюся политику занижения прогнозных цен на энергоносители, «излишки» от которых вкладываются не в развитие отечественной экономики, а в соответствующие резервные фонды, разительные перекосы в соотношении федерального и региональных бюджетов (когда основные расходы перекладываются на региональный и местный уровень), неадекватность управления государственным имуществом (приватизация наиболее доходных государственных активов), столь же неадекватные промышленную и кредитно-денежную политику (работающих в интересах естественных монополий, но не в интересах основной массы населения, а также мелкого и среднего бизнеса). Анализ данной ситуации вполне естественно приводит к следующему выводу: «...подобная социально-экономическая политика свидетельствует о том, что вопреки риторике основной задачей российского государства попрежнему является всемерный учет и продвижение интересов сформировавшейся в последнее двадиатилетие политико-экономической элиты и ее зарубежных партнеров. И потому нехватка бюджетных средств - следствие описанной выше политики - компенсируется за счет усиления разного рода поборов с большинства населения, перекладывания на население все большего объема платежей в социальной сфере, фактического регресса в социальных обязательствах государства, снижения доступности качественного образования и здравоохранения для существенной части россиян» (там же: 61-62; курсив мой. - Г. К.).

Здесь возникает закономерный вопрос: что за политико-экономическая система сложилась в настоящее время в России, каковы ее природа и особенности функционирования? Эту систему другие авторитетные исследователи характеризуют как абсолютное доминирование государственной бюрократии при одновременной слабости («рыхлости») государства. Так, отечественный исследователь социального государства политолог А. Ф. Храмцов в своих работах предлагает именовать данную систему «бюролиберализмом», обозначая этим термином всевластие бюрократии, фактически существующей исключительно ради собственных узкокорпоративных интересов, но мимикрирующей под некий прогрессивный либеральный правящий класс, действующий во имя общего блага и - главное - в полном соответствии с мировыми стандартами социального государства (Храмцов, 2010). Однако, как убедительно показывает исследователь, реальная ситуация такова, что в России фактически создано соииальное государство для бюрократии, которое вполне успешно функционирует на трех уровнях (или ярусах) - федерального бюджета, уровне внебюджетньх фондов и на остаточном уровне простого населения, - осуществляя политику перераспределения не "сверху вниз», как в нормальных европейских социальных государствах, а наоборот, «снизу вверх», т. е. исключительно в интересах правящего класса. Храмцов справедливо пишет: «...в России, учитывая ее дифференциацию по доходам, финансы должны были бы перетекать “сверху вниз" значительно более отвесно, чем в классических социальных государствах. Реально же социальную политику России можно сравнить с гигантским гейзером, выбрасывающим огромные финансовые средства, предназначенные на социальные нужды, на верхний ярус российского общества» (там же: 140). Попросту говоря, ситуация такова, что нормальное социальное государство не может реализоваться из-за нехватки средств, а нехватка эта вызвана тем, что средства, предназначенные на нужды социальной политики, попросту растрачиваются государственной бюрократией на собственные нужды. При этом весьма характерно поведение самой бюрократии, которая, с одной стороны, стремится сбро- 
сить с себя максимум социальных обязательств и уйти из сфер, требующих высокой квалификации и ответственности, а с другой - максимально нарастить свое влияние в тех сферах, где требуются разного рода разрешительно-запретительные мероприятия, как и в таких, где осуществляются сделки по приватизации имущества. То есть, иными словами, российская бюрократия действует максимально безответственно, некомпетентно, в ущерб интересам основного населения страны, но такое положение вещей сохраняется постольку, поскольку население не видит реальной альтернативы сложившемуся порядку. Реальным выходом из данного положения могли бы стать политическая демократизация (и прежде всего создание конкурентной партийно-политической системы, формирующей независимую законодательную власть, а также правительство) и развитие институтов гражданского общества, однако надежды на скорое изменение ситуации в этих сферах весьма и весьма небольшие.

Таким образом, перспективы цивилизованного развития социального государства в России по-прежнему остаются весьма туманными, по крайней мере до тех пор, пока реально не изменится сама политико-экономическая структура российского общества (т. е. не произойдут реальная дебюрократизация и рост влияния гражданских, низовых структур). Сложившееся же положение (особенно рост коррупции, захвативший все сферы общества и структуры государственного управления) создает крайне опасную ситуачию в плане устойчивого развития российского общества в условиях глобальных вызовов.

\section{ЗАКАЮЧЕНИЕ}

И самое последнее, о чем стоит сказать, - это направление развития социального государства в России, выбор модели, которой должна следовать социальная политика. Известны три основные модели социального государства (континентальная консервативная, англосаксонская - либеральная, скандинавская - социал-демократическая) (см., например: Канарш, 2018). Четвертой моделью выступает советская социалистическая. К какой из них в идеале должна стремиться политика современного российского государства? Как отмечается в некоторых исследованиях (см., например: Кормщиков, 2014), общемировая тенденция сегодня такова, что практически нет стран, в которых бы реализовалась та или иная модель социальной политики в чистом виде. В конкретной политике стран так или иначе воплощаются черты разных моделей. В русле той же общемировой тенденции находится сегодня и Россия. Так, в социальной политике современного российского государства обнаруживаются черты как либеральной (свобода занятости, адресность социальной помощи), так и континентальной (принципы социального страхования, основанные на индивидуальных отчислениях и вычетах с заработной платы) модели. При этом если говорить о приоритетах населения, то они однозначно склоняются в сторону соииал-демократической модели. В то же время справедливо подчеркивается, что реализация социал-демократической модели в ее классическом варианте в современной России невозможна, и прежде всего по причине высокой нагрузки на бюджет (как федерального, так и регионального уровня). Поэтому более реалистичным выглядит вариант создания смешанной интегральной модели, в рамках которой сочетались бы черты разных типов социальной политики (там же: 443). Возможно, одним из ключевых элементов этой модели могла бы стать прогрессивная шкала налогообложения, характерная в большей мере для социал-демократического режима и в значительной мере отвечающая перераспределительным настроениям основной массы населения России. 
И все же немалая проблема создания социального государства в современном российском обществе заключается в по-прежнему высоком уровне надежд населения на позитивное вмешательство в социальные процессы со стороны государства, при том что сам характер российской государственности, как он сложился на сегодняшний день, явно не соответствует этим массовым ожиданиям (см., например: Что осталось от «социального государства» ..., 2015: Электронный ресурс). В этом заключается немалая опасность, поскольку кредит доверия государству может раньше или позже закончиться. А это, в свою очередь, может быть чревато самыми драматическими последствиями для стабильного существования российского общества.

\section{СПИСОК АИТЕРАТУРЫ}

Александрова, О. А. (2013) Социальное государство в современной России: развитие или демонтаж// Вестник РГГУ. № 15 (116). С. 56-57.

Канарш, Г. Ю. (2018) Социальное государство: исторический генезис и современные модели // Знание. Понимание. Умение. № 1. С. 128-142. DOI: 10.17805/zpu.2018.1.10

Кормщиков, А. А. (2014) К какой модели социальной политики стремится Россия? // Вестник Нижегородского университета им. Н. И. Аобачевского. № 1 (2). С. 439-444.

Кочеткова, А. Н. (2012) Философский дискурс о социальном государстве. М. : ИНФРА-М. 216 c.

Һюблинский, В. В. (2017) Социальная справедливость, рост неравенства и проблема сплоченности общества: международные тенденции // Социальная справедливость в современном мире : сб. ст. / [редкол.: А. И. Никовская (отв. ред.), В. Н. Шевченко, В. Н. Якимец]. М. : КлючC. 446 c. C. $105-115$.

Милютин, В. А. (1946) Пролетарии и пауперизм в Англии и во Франции. Статья первая // Милютин, В. А. Избранные произведения. М. : ОГИЗ ; Государственное издательство политической литературы. 445 с. С. 158-237.

Сидорина, Т. Ю. (2013) Государство всеобщего благосостояния: от утопии к кризису. М. : РГГУ. 349 с.

Федотова, В. Г. (2005) Хорошее общество. М. : Прогресс-Традиция. 544 с.

Храмцов, А. Ф. (2010) Бюрократия и социальное государство. М. : ИС РАН. 242 с.

Что осталось от «социального государства». Экономист Евгений Гонтмахер о неэффективной модели госуправления, боязни реформ во власти и кризисе человеческого капитала (2015) [Электронный ресурс] // Новая газета. 6 июля. С. 2-3. URL: https://www.novayagazeta.ru/articles/2015/07/04/64785-ekonomist-evgeniy-gontmaher-chto-ostalos-ot-sotsialnogo-gosudarstvarossiya (дата обращения: 19.03.2018)

Аата поступления: 20.03.2018 г.

\section{SOCIAL STATE IN RUSSIA: HISTORY AND MODERNITY}

\section{G. YU. KANARSH \\ RAS INSTITUTE OF PHILOSOPHY}

This article is devoted to the issue of the formation of a social state in contemporary Russia. Despite the crisis of welfare state in the West (due to globalisation), which is noticed by many researchers, it is necessary to create a social state in our country. The existence of huge social inequality indicates the absence of this institute, its disarrangement.

The author refers to the genesis of building a social state in Russia. The opinions of different authors on whether the Soviet socialist state was social are given. The author shares the view that the Soviet state was not social in the true sense of the word, since a classic social state includes the institution of a bourgeois society, through which a class compromise is achieved. At the same time, there is no doubt that the socialist state, despite its original class nature, performed the most important social functions. 
The article describes the main stages of the formation of a social state in post-Soviet Russia. The author agrees with the opinion of those researchers who believe that this state is still not formed in Russia. The main reason for this is the existing political and economic system in the country. Drawing on a number of studies of economists and political scientists, the article shows that the current «social state» in Russia is built in such a way that it expresses the interests of the dominant class - the ruling bureaucracy. And the only way out of this situation is the strengthening of control over the government on the part of the civil society and competitive political institutions.

Under the existing system of relations between the authorities and society, the prospects of a social state in Russia look rather vague until there are changes in the political and economic structure of Russian society.

Keywords: social state; social policy; Soviet state; social classes; class compromise; social insurance; bureaucracy; democracy; Russia

\section{REFERENCES}

Aleksandrova, O. A. (2013) Sotsial'noe gosudarstvo v sovremennoi Rossii: razvitie ili demontazh. Vestnik RGGU, no. 15 (116), pp. 56-57. (In Russ.)

Kanarsh, G. Yu. (2018) Sotsial'noe gosudarstvo: istoricheskii genezis i sovremennye modeli. Znanie. Ponimanie. Umenie, no. 1, pp. 128-142. DOI: 10.17805/zpu.2018.1.10 (In Russ.)

Kormshchikov, D. A. (2014) K kakoi modeli sotsial'noi politiki stremitsia Rossiia? Vestnik Nizhegorodskogo universiteta im. N. I. Lobachevskogo, no. 1 (2), pp. 439-444. (In Russ.)

Kochetkova, L. N. (2012) Filosofskii diskurs o sotsial'nom gosudarstve. Moscow, INFRA-M. 216 p. (In Russ.)

Liublinskii, V. V. (2017) Sotsial'naia spravedlivost', rost neravenstva i problema splochennosti obshchestva: mezhdunarodnye tendentsii. In: Sotsial'naia spravedlivost' $v$ sovremennom mire / L. I. Nikovskaia, V. N. Shevchenko, V. N. Iakimets (eds). Moscow, Kliuch-S. 446 p. Pp. 105-115. (In Russ.)

Miliutin, V. A. (1946) Proletarii i pauperizm v Anglii i vo Frantsii. Stat'ia pervaia. In: Miliutin V. A. Izbrannye proizvedeniia. Moscow, OGIZ, Gosudarstvennoe izdatel'stvo politicheskoi literatury. $445 \mathrm{p}$. Pp. 158-237. (In Russ.)

Sidorina, T. Yu. (2013) Gosudarstvo vseobshchego blagosostoianiia: ot utopii k krizisu. Moscow, RGGU. 349 p. (In Russ.)

Fedotova, V. G. (2005) Khoroshee obshchestvo. Moscow, Progress-Traditsiia. 544 p. (In Russ.)

Khramtsov, A. F. (2010) Biurokratiia i sotsial' noe gosudarstvo. Moscow, ISRAN. 242 p. (In Russ.)

Chto ostalos' ot «sotsial'nogo gosudarstva». Ekonomist Evgenii Gontmakher o neeffektivnoi modeli gosupravleniia, boiazni reform vo vlasti i krizise chelovecheskogo kapitala (2015). Novaia gazeta, 6 Jule, Pp. 2-3. [online] Available at: https://www.novayagazeta.ru/articles/2015/07/04/64785ekonomist-evgeniy-gontmaher-chto-ostalos-ot-sotsialnogo-gosudarstva-rossiya (access date: 19.03.2018). (In Russ.)

Submission date: 20.03 .2018$.

Канарш Григорий Юрьевич - кандидат политических наук, старший научный сотрудник сектора социальной философии Института философии РАН. Адрес: 109240, Россия, г. Москва, ул. Гончарная, д. 12, стр. 1. Тел.: +7 (495) 697-98-93. Эл. адрес: grigkanarsh@yandex.ru

Kanarsh Grigory Yurievich, Candidate of Political Sciences, Senior Research Fellow, Sector of Social Philosophy, RAS Institute of Philosophy. Postal address: 12, Bldg. 1, Goncharnaya St., Moscow, Russian Federation, 109240. Tel.: + 7 (495) 697-98-93. E-mail: grigkanarsh@yandex.ru 